\title{
Cholera and household water treatment why communities do not treat water after a cholera outbreak: a case study in Limpopo Province
}

\author{
Lutendo Sylvia Mudau ${ }^{\mathrm{ab} *}$, Murembiwa Stanley Mukhola and Paul Raymond Hunter ${ }^{\mathrm{a}}$ \\ ${ }^{a}$ Norwich School of Medicine, University of East Anglia, UK \\ ${ }^{b}$ Environmental Health Department, Tshwane University of Technology, Pretoria, South Africa \\ *Corresponding author, email:MudauLS@tut.ac.za
}

\begin{abstract}
Background: Cholera is one of the common diseases in developing countries caused by consumption of contaminated and untreated drinking water. A study was conducted 7 months after a cholera outbreak in Vhembe district, Limpopo, South Africa. The aim of the study was to assess if the communities were still conforming to safe water practices after an outbreak of cholera. Methodology: One hundred and fifty-two (152) participants from 11 villages were recruited to form 21 focus groups, with a mean of 7. The interview transcripts were coded and arranged based on the study themes.

Results: Of the 21 groups in 11 villages, three villages were using water from boreholes, six were using river water and three were using mixed sources which included river, canal and spring water, three depended on municipal tanks and only six were using tap water. Only $19 \%$ of the respondents treated their water, even though the majority of communities reported treatment of water as a priority. Four villages claimed they never received environmental health education at all, while most of the villages confirmed they received education during a cholera outbreak.

Conclusion: Regardless of the outbreak and health education efforts done, communities continued using unprotected water sources without any form of treatment, as they perceived it to be unimportant. Sustainable water supplies and environmental health education should be continued after an outbreak as it is important for public health gains.
\end{abstract}

Keywords: cholera outbreak, communication, drinking water, health education, household water, safe practices, water treatment

\section{Introduction}

Cholera is probably the most feared cause of acute diarrhoea due to its high mortality, especially in children under the age of five. ' Contaminated drinking water is probably the most common cause of cholera especially in poor and vulnerable communities. Sub-Saharan countries have been affected by the disease on frequent occasions in recent decades, ${ }^{2}$ and approximately $93 \%$ to $98 \%$ of total cholera cases were reported from Africa. ${ }^{3}$ Communities in Limpopo province, Vhembe district municipality, experienced a cholera outbreak from November 2008 to April 2009; and, a total of 720 cases were confirmed. ${ }^{4}$ Farmworkers residing adjacent to rivers had no toilets and drinking water infrastructure. They practiced open defaecation and drank water from the river. Human movement caused the cholera outbreak to spread from Zimbabwe to South Africa (SA), with contributing factors including the use of contaminated drinking water and a lack of sanitation infrastructure. ${ }^{5,6}$

Globally, approximately six to nine million people die annually from water-related diseases. ${ }^{7,8}$ The majority of these people reside in developing countries with inadequate water and sanitation services. The emergence of cholera in Limpopo province has also provided evidence that it was partly due to a lack of access to safe water by the communities and poor environmental health practices. ${ }^{9}$

Reliable safe water at household level remains a key issue in accelerating the health and welfare of the communities. ${ }^{10}$ Unfortunately, most communities in rural areas of SA are not accessing sufficient water for all domestic use and have to rely, in part, on alternate sources. ${ }^{11}$ Inconsistent water supply in communal water sources brings a great deal of uncertainty to the health risks of the communities as community members are forced to use alternative, unmonitored water sources. ${ }^{14}$ Women and children, in particular, are the most affected; ${ }^{12-15}$ therefore, provision of safe water without contamination and risking the health of consumers is key in water service delivery. ${ }^{16}$

In a bid to control cholera outbreaks in Vhembe district municipality (VDM), the health promoters embarked on a campaign to educate the communities on the importance of using toilets, hand washing, personal hygiene, safe water storage and treatment by boiling and using chemicals. ${ }^{17,18}$ Consequently, the information that is usually given once-off loses its impact after a few days, leading to a lower response rate from the community to change their behaviour on hygiene practices.

\section{Materials and methods}

The study was conducted in 11 rural villages of VDM, in Limpopo province, situated next to the border of South Africa and Zimbabwe, as a follow-up after a cholera outbreak in 2008 and 2009. Data was collected 7 months after the outbreak. Twentyone groups were recruited to take part in the study. Consent was obtained from all participants prior to data collection.

A total of 152 participants were involved in the study. There were more females (142) participating than males (10). Twenty-one focus groups participated, with a mean of 7 . A structured interview guide was used. The selection criteria used was that all participants should be living in the same village where the study was being conducted; should have witnessed the cholera outbreak; and, each one of them should represent one household. The same set of questions were analytically divided 
into water supply, water availability, water treatment, and communication and environmental health education provided.

\section{Data analysis}

The interview transcripts were coded and arranged based on study themes. Respondents examined the data to identify descriptive explanations by the participants. The structured interview guide was used to ensure that similar topics were discussed among the groups.

\section{Results}

Water supply and availability: Information gathered from the respondents indicated that, prior to 1996, there was no piped water service in the area and all villages relied on rivers, springs and canals for their domestic supply of water. Taps were installed in eight of the 11 villages between 1998 and 2008, however most were dry. Communities were using various water sources during the time of the survey. Of the 21 groups in 11 villages, three villages were using water from boreholes, six used river water, three used mixed sources including river, canal and spring water, three depended on municipal tanks while only six used taps, as indicated.

Though the Municipality provided water from tanks in some of the villages, the provision of water was not consistent as the volume of water allowed for collection was only 20 litres or 25 litres per household per day. Consequently, the communities used river water as their alternative supply. On the day of the interview, only six groups from three villages claimed to be sourcing their drinking water from the village taps. Scheduling of opening and closing tap water in five villages was for a period of up to four hours per day. However, the view of one of the groups on availability of water was:

"There is no water from the drilled well - it seems it has dried out. Water is only pumped from $16 \mathrm{~h} 00$ to $18 \mathrm{~h} 00$. We now use borehole water for drinking as well as spring and river for other activities."

The reason why group members with locally installed taps were not using the tap water was that the taps were dry on the day of the visit. Groups that were using tap water on the day of the visit claimed their water source was generally available. Only two of the six groups commented that their tap did not always have water, as per the following comment:

"Sometimes the water is not available for the whole week. The tap is scheduled from 15h00-17h30. The drilled water is now dry and the water is no longer available. We are waiting for the VDM Technicians to come and fix it."
In one group, the participants reported they used river water and in another group, they walked to other taps further away. It was noted that people who were using supplied sources often had to resort to river water. Three groups from two villages who had water delivered by tanker stated that they had to revert to river water regularly because of delays in delivering the water. Though 17 out of the 21 groups reported having communal taps installed in their villages, only six (29\%) were using these taps on the day of the visit.

The only other improved water supply was boreholes, used by three groups from two villages. Consequently, 12 of the 21 (57\%) groups reported using river, spring and canal water on the day of the visit. Another group reported that although they were using tap water on the day of the visit, they often had to revert to river water during failures in water supply.

Water Treatment: Table 1 indicates that water treatment was practised by only $19 \%$ of respondents, while $71 \%$ did not treat their water at all. The majority of people boiled their water (11\%), while $8 \%$ preferred to use chemicals.

When asked why they did not treat river water, the community generally did not think this was important. A typical and common comment cited was:

"We do not treat water from the river because it is long time that we drink the water and nothing happened to us."

Water access: Difficulties were noted amongst the communities where tank water was provided by the VDM. The time schedule for the provision of water was not consistent. Communities were forced to go back to the river, which was a distance of more than $200 \mathrm{~m}$. The respondents comment from the villages without taps was:

"The tanker took up to two weeks without delivering the water and then we go back to the river."

The majority of the communities where tap water was provided were satisfied with the distance from the water source; one village was not happy with the distance between unimproved and improved water sources. One of the group members reported they still use water from the canal for domestic chores as it was nearer than the tap water source. The comment was:

"Those who are living next to canal are still using the water for domestic chores due to nearer distance compared to taps."

\begin{tabular}{|l|c|c|c|}
\hline \multirow{2}{*}{ Water sources } & \multicolumn{2}{|c|}{ Frequency } & \multirow{2}{*}{ Total } \\
\cline { 2 - 4 } & Boiling & Chemical treatment & $3(2 \%)$ \\
\hline Borehole & $2(1 \%)$ & $1(1 \%)$ & $9(6 \%)$ \\
\hline Canal & $4(3 \%)$ & $5(3 \%)$ & $9(6 \%)$ \\
\hline Siver & $6(4 \%)$ & $3(2 \%)$ & $4(3 \%)$ \\
\hline Tank & $2(1 \%)$ & $2(1 \%)$ & $1(1 \%)$ \\
\hline Tap & $0(0 \%)$ & $1(1 \%)$ & $3(2 \%)$ \\
\hline Total & $3(2 \%)$ & $0(0 \%)$ & $29(19 \%)$ \\
\hline
\end{tabular}


Table 2: Types of communication provided to the communities

\begin{tabular}{|c|c|c|}
\hline Village Name & Health Education related to water & Type of communication often made \\
\hline Village 1 & No health education & $\begin{array}{l}\text { Community involved in project communication and } \\
\text { communication of fees for operator payment. }\end{array}$ \\
\hline Village 2 & Education provided only during Cholera outbreak & $\begin{array}{l}\text { Communication based on the phone call made to } \\
\text { VDM to provide tank water }\end{array}$ \\
\hline Village 3 & Education provided only during Cholera outbreak & $\begin{array}{l}\text { Communication done when there is water system } \\
\text { breakdown and communication of fees for operator } \\
\text { payment. }\end{array}$ \\
\hline Village 4 & No health education & Communication of fees for operator payment \\
\hline Village 5 & Education provided only during Cholera outbreak & Communication of fees for operator payment \\
\hline Village 6 & No health education & $\begin{array}{l}\text { Communication done when water schedule was } \\
\text { proposed and communication of fees for operator } \\
\text { payment }\end{array}$ \\
\hline Village 7 & Education provided only during Cholera outbreak & No communication \\
\hline Village 8 & Education provided only during Cholera outbreak & $\begin{array}{l}\text { Communication done when there is water system } \\
\text { breakdown }\end{array}$ \\
\hline Village 9 & Education provided only during Cholera outbreak & Communication done when there is water shortage \\
\hline Village 10 & Education provided only during Cholera outbreak & $\begin{array}{l}\text { Communication was based on the new project in } \\
\text { progress }\end{array}$ \\
\hline Village 11 & No health education & $\begin{array}{l}\text { Communication done when there is water system } \\
\text { breakdown and communication of fees for operator } \\
\text { payment. }\end{array}$ \\
\hline
\end{tabular}

Tap water was preferred for drinking purposes. In one village, where distance to communal taps ranged from $300 \mathrm{~m}$ to $500 \mathrm{~m}$ from the household, old people complained of back pains as a result of fetching water and the distance travelled to the tap. They preferred the provision of water in their yard but could not afford the connection fee. The comment from the groups supplied with water was:

"The water is safe and nearer to households, but we need water in the household yard but we cannot afford money for household water connection. Some of us are too old to reach the taps on the street."

Communication and Environmental Health education: Table 2 shows the type of communication given to the community after the cholera outbreak. The investigation was based on the communication related to health education and other types of water service communication passed to the community. All groups in all villages indicated there was no on-going health education related to water. In three villages, groups claimed that no health education was ever provided to them.

The communities in all villages often received water-related communication other than the information addressing health risks. Such communications included payment of monthly fees to the operator; hiring of the vehicle to collect diesel for water pumps; communication in case of water shortages and breakdown in providing tank water by the VDM; as well as, communication on water scheduling and project implementation. In summary, water education related to health risks was not provided.

\section{Discussion}

Despite the cholera outbreak, which occurred 7 months prior to the study's commencement, treatment of water by the respondents was not seen as a priority and was done by only a few households. Problems accessing potable water were common in the area. The community continued using untreated water sources for consumption as they thought it was not important to treat it. However, unreliable water service and environmental hygiene were reported as the main causes of the cholera outbreak. ${ }^{19}$ The unavailability of potable water in communities encouraged communities to use unimproved sources, which is described as water sources that include an unprotected dug well, unprotected spring, tanker truck, surface water and bottled water. ${ }^{20} \mathrm{An}$ improved water source is described as the use of piped water connected in a household yard, public tap, tube well or borehole, protected spring, protected dug well and rain water collection. ${ }^{20}$ Despite improved water sources having been provided in the area, the communities continued to use unimproved water sources as their alternative supply.

The presence of pathogenic cholera bacteria that were detected in cattle manure in research conducted in the Vhembe district, Limpopo province, raise a concern when utilising unimproved sources. Cattle were observed drinking water from the same rivers and springs used by the communities as their alternative supply. ${ }^{21}$ This situation highlighted the urgent need for a sustainable water-supply service and health education to ensure the community would take reasonable steps to ensure their water was safe to use.

Unavailability of potable water was also common, mainly due to infrastructure breakdown and low water capacity in drilled wells. Most of the groups interviewed confirmed the unavailability of water. These problems led to poor water scheduling and unavailability of water for weeks, months and sometimes up to a whole year. One of the studies conducted in the area by Majuru et al. ${ }^{22}$ confirmed an increase in the number of cases of acute diarrhoea in households during water cut-off times. The use of unimproved sources could lead to poor health gains if water treatment and hygiene education on water treatment and environmental health practices are not provided. The lack of education on safe water management is a concern as this could lead to risks of water related diseases to communities. ${ }^{23}$ Therefore, communities should be empowered and supported and know 
the steps to take to reduce their exposure to harmful bacteria and learn to manage their own health and safety.

The need for household water treatment at the point of use is of critical importance in the prevention of cholera, and such initiatives should be underpinned by health and hygiene education in order to improve the level of health literacy within these communities. The majority of the respondents in these communities were not treating their water and only a few were treating water through boiling and disinfection. Respondents who relied on river, spring and canal water for household purposes often used chemical treatment. It is the fastest and most reliable method used to manage outbreaks in various countries and was recently used in SA to eradicate cholera outbreaks. ${ }^{24}$

The inability of communal water sources to provide consistent water supply could bring a lot of health risks and challenges in communities when unsafe water sources are used. The situation will require appropriate measures to be taken. However, the results indicated that water treatment is taken seriously when there is a life-threatening situation. Subsequently, information given by health workers on water treatment during the outbreak was not taken seriously by most of the community members after the cholera outbreak. The study indicated that proficient health literacy skills on the management of their health for prevention of disease were lacking in these communities.

Therefore, the public health education provided to the communities, which depend on unsafe water, did not contribute much to bring about behavioural change in the community. The appropriate communication channels are appropriate to ensure that health information translates into long-term healthy behaviour.

In conclusion, the use of multiple water sources by communities because of an unreliable primary supply makes management of water safety at the household level very complex. Even in the aftermath of a cholera epidemic, consumers are not likely to practice safe water treatment in the home. From our research there are several reasons why consumers may not practice safe water treatment and storage. One of the key reasons appears to be the failure of the local water supplies to deliver water reliably, forcing consumers to use less safe sources. The other is that there remains scepticism among community members about the hazards of unsafe drinking water. During a cholera outbreak, those agencies responsible for drinking water safety need to ensure that the reliability of safe water supplies are improved. Such agencies also need to take the opportunity of the epidemic to reinforce key messages about safe water management in the home. However, these educational messages need to be continued in the post-epidemic period to ensure that safe practices are maintained.

Acknowledgements - The authors would like to acknowledge, with thanks, the contributions made by the Tshwane University of Technology, Medical Research Commission of South Africa and Wellcome Trust through SNOWS, for guidance, support and financial assistance.

\section{References}

1. Rosa G, Clasen T. Estimating the scope of household water treatment in low and medium-income countries. Am J Med Hyg. 2010;82(2):289-300.

2. World Health Organization. Cholera surveillance and number of cases annual summary (1989-2010) [cited 2011 Jun]. 2010. Available from: http://www.who.int/gho/epidemic-topics/cholera/surveillence/en/ index.htm.
3. Mugoya I, Kariuki S, Galgalo T, et al. Rapid spread of Vibrio cholerae O1 throughout Kenya. Am J Med Hyg. 2005;78(3):527-33.

4. Ismail H, Smith AM, Tau NP, et al. Cholera outbreak in South Africa, 2008-2009 laboratory analysis Vibrio cholera O1strains. SAJID. 2013;208(1):39-45.

5. National Institute for Communicable Disease Control. Communicable disease communique [cited 2012 Mar]. 2009;8(4). Available from: http://www.nicd.ac.za/assets/files/NICDCommApr09Vol08_04.pdf.

6. Department of Water Affairs. Media release: water affairs and forestry minister visited Limpopo, Pretoria, South Africa [cited 2009 Nov]. Available from: https://www.dwa.gov.za/.../ MinisterHendricksVisitsLimpopo-Cholera12March2009.pdf.

7. United Nations. The millennium development goals report. 2013;46-9. Available from: http://www.un.org/millenniumgoals/pdf/ report-2013/mdg-report-2013-english.pdf.

8. World Health Organisation, United Nations Children's Fund. The millennium development goals report [cited 2014 Nov]. 2012;469. Available from: http://www.un.org/millenniumgoals/pdf/ report-2013/mdg-report-2013-english.pdf.

9. Nnaji CC, Eluwa C, Nwoji C. Dynamics of domestic water supply and consumption in a semi-urban Nigerian city. Habitat Int. 2013;40:127-35.

10. Prüss-üstün $A$, Bos R, Gore $F$, et al. Safer water, better health: costs, benefits and sustainability of interventions to protect and promote health [cited 2011 Nov]. 2008;1-21. Available from: http://whqlibdoc. who.int/publications/2008/9789241596435_eng.pdf.

11. Evans B, Bartram J, Hunter P.et al. 2013. Public health and social benefits of at-house water supplies [cited 2010 Nov]. 2013;3-35. Available from: http://www.r4d.dfid.gov.uk/.../water/61005DFID_ HH_water_supplies_final_report.pdf.

12. Hemson D. The toughest of chores: policy and practice in children collecting water in South Africa. Policy Futures in Edu. 2007;5(12):315-24.

13. Hawkins R, Seager J. Gender and water in Mongolia. Professional Geographer. 2010;62:16-31.

14. Arku FS. Time savings from easy access to clean water. Implications for rural men's and women's well-being. Prog Dev Stud. 2010;10(3):233-46.

15. Majuru $B$, Jagals $P$, Hunter $P$. Assessing rural small community water supply in Limpopo, South Africa: water service benchmarks and reliability. Sci Total Environ. 2012;435:479-86.

16. Hunter $P$, Pond $K$, Jagals $P$, et al. An assessment of the costs and benefits of interventions aimed at improving rural community water supplies in developed countries. Sci Total Environ. 2009;407(12):3681-5.

17. Said MD, Fuke N, Jacobs I, et al. The case of cholera preparedness, response and prevention in the SADC region: a need for proactive and multi-level communication and co-ordination. Water South Africa. 2011;37(4):559-66.

18. Department of Health. Statement by the Minister of Health Barbara Hogan on the outbreak of cholera in Zimbabwe and South Africa [cited 2009 Nov]. Media Room. 2008:1-2. Available from: http://www. academia.edu/.../Leaving_behind_a_twisted_soul_the_2008-2009_ cholera_outbreak_in_South_Africa.

19. United Nations Children's Fund. Cholera outbreak South Africa National Outbreak Committee situational report (Sitrep 29) as of 12:00 hrs 11th January [cited $2010 \mathrm{Jul}] .2009 ; 1-5$. Available from: http://www.unicef.org/southafrica/SAF_emergency_cholera29.pdf.

20. World Health Organization/ United Nations Children's Fund. Joint Monitoring Programme for Water and Sanitation Progress on Sanitation and Drinking Water [cited $2013 \mathrm{Jan}$ ]. 2008. Available from: http://www. who.int/water_sanitation_health/monitoring/jmp2008/en.

21. Keshav V, Potgieter N, Barnard TG. Detection of Vibrio cholerae 01 in animal stools collected in rural areas of the Limpopo Province. Water SA. 2010;36(2):167-71.

22. Majuru $B$, Mokoena MM, Jagals $P$, et al. Health impact of smallcommunity water supply reliability. Int J Hygiene Environ Health. 1016;10(1016):1-5.

23. Mokoena M. The effect of water-supply service delivery on the risk of infection posed by water in household containers. M.S.C dissertation. University of Johannesburg Library, 2009

24. Clasen TF. Household water treatment in poor populations: is there enough evidence for scaling up now? Environ Sci Technol. 2009;43(4):986-99. 